\title{
Evaluation of Frost Resistance in Cellular Concrete Containing Cement-Fly Ash-Lime
}

\author{
Chang-Seon Shon ${ }^{1,}$, Dan G. Zollinger ${ }^{2, b}$ \\ ${ }^{1}$ Department of Civil Engineering, Nazarbayev University, 53 Kabanbay Batyr Ave., \\ Astana, 010000, Kazakhstan \\ ${ }^{2}$ Zachry Department of Civil, 501D CVLB, College Station, Texas 77843, USA \\ achang.shon@nu.edu.kz, bd-zollinger@tamu.edu
}

Keywords: Cellular concrete, Freeze-thaw resistance, Porosity, Dynamic modulus of elasticity

\begin{abstract}
Cellular concrete (CC) is a foamed mixture of cementitious materials, fine sand, and water, which once hardened results in a consistent, lightweight concrete containing millions of evenly distributed, uniformly sized macroscopic air-voids of approximately 0.1 to $1 \mathrm{~mm}$ size. In the present study, cellular concretes with varying proportions of portland cement, fly ash, and lime were explored in a comprehensive laboratory test program related to porosity, compressive strength and resistance to Freeze-Thaw (F-T) including dynamic modulus of elasticity. Test results show that compressive strength of cellular concrete is primarily as a function of the porosity and w/cm regardless of type of cementitious material and curing age. On the other hand, the CC mixture with high porosity does not necessarily result in higher resistance of F-T, but the CC concrete generally has good F-T resistance compare to non-aerated concrete.
\end{abstract}

\section{Introduction}

Cellular concrete (CC), a special type of lightweight building material, was originally developed in Europe but is now being used all over the world. It is produced by mixing cement and/or lime, silica-rich material (sand, slag, or fly ash), water, and a forming admixture to form a uniform cellular structure of air voids of approximately 0.1 to $1 \mathrm{~mm}$ size. [1].

Incorporating the air-voids into either cement paste or mortar matrix provides lightweight, high insulating values, and lower strength when compared to normal-weight concrete. Narayanan and Ramamurthy [2] reported that the pore structure of CC consists of gel pores, capillary pores as well as air-voids (air entrained and entrapped pores) in a similar fashion with normal concrete. However, most of previous researches [3-6] have been focused on the relationship between air-void system and compressive strength including empirical modeling to predict strength of CC.

Few reports have discussed the performance of freeze-thaw (F-T) resistance of CC. The most common and critical failure modes of CC in F-T are surface scaling and spalling because CC contains largely free water or absorbed water due to water absorption from surface [7]. Tikalsky et al. [1] reported that compressive strength, depth of initial penetration, absorption and absorption rate are important variables in F-T resistance of CC.

In the present study, cellular concretes with varying proportions of portland cement, fly ash, and lime were explored in a comprehensive laboratory test program related to porosity, compressive strength and F-T resistance including dynamic modulus of elasticity.

\section{Experimental Program}

The framework for the proposed experimental program to be carried out is summarized in Table 1. The suggested laboratory testing program focused on three areas of interest: (i) characterization of fresh and hardened properties on cellular concrete specimen such as wet and hardened unit weight, absorption capacity, and water permeable porosity and (ii) evaluation of F-T resistance of CC relative to ASTM C 1262 Evaluation of the Freeze-Thaw Durability of Concrete Units, and 
dynamic modulus of elasticity.

Table 1. Experimental program.

\begin{tabular}{l|l|l|l}
\hline \multicolumn{1}{c|}{ Test Attribute } & \multicolumn{1}{|c|}{ Analytical Method } & $\begin{array}{c}\text { ASTM Specification/ } \\
\text { References }\end{array}$ & Measured Properties \\
\hline Fresh Properties & Wet unit weight & ASTM C 140 & Density \\
\hline \multirow{2}{*}{ Hardened properties } & Hardened unit weight & ASTM C 140 & Density \\
\cline { 2 - 4 } & Absorption & ASTM C 140 & Absorption capacity \\
\cline { 2 - 4 } & $\begin{array}{l}\text { Water permeable } \\
\text { porosity }\end{array}$ & $\begin{array}{l}\text { Vacuum saturation } \\
\text { method }\end{array}$ & Porosity \\
\hline Freeze thaw resistance & F-T resistance & ASTM C 1262 & F-T resistance \\
\cline { 2 - 4 } & $\begin{array}{l}\text { Dynamic modulus of } \\
\text { elasticity }\end{array}$ & Resonant frequency & Durability factor \\
\hline
\end{tabular}

\section{Materials Mixture Proportions}

Cementitious materials used in this study included an ASTM Type I Portland cement, ASTM Class F fly ash, and lime. Masonry sand meeting the specification of ASTM C 144 was used in the mixture. The sand had 100 percent passing the \# 8 sieve, an absorption capacity of $1.01 \%$, and a specific gravity of 2.57 . The foaming admixture was diluted with water at a ratio of 1 to 60 (by volume) and then aerated under pressure to create the foam.

A total of 12 mixtures were evaluated. The mixture proportions are given in Table 2. Test mixtures were prepared under laboratory conditions. To evaluate the effect of air content on freeze-thaw resistance of CC and its fresh and hardened properties, these mixtures were further categorized into 2 series; Series I and II. Four mixtures in Series I did not contain forming admixture and was combined with cement, fly ash, and lime and water to cementitious material ratio $(\mathrm{w} / \mathrm{cm})$ of 0.60 . Series II mixtures was proportioned with cement-fly ash-lime or cement-lime blends with $30 \%$ and $50 \%$ air contents with the same w/cm as Series I.

Table 2. Mixture proportions.

\begin{tabular}{l|c|c|c|c|c|c|c}
\hline \multirow{2}{*}{ Mixture } & \multirow{2}{*}{ W/CM } & \multicolumn{7}{c}{ Unit Weight $\left({\left.\mathrm{lb} / \mathrm{cy}^{3}\right)}^{3}\right.$} \\
\cline { 3 - 8 } & & Water & Cement & Fly ash & Lime & Sand & Foam \\
\hline C-33L-25FA-0 & 0.60 & 507.6 & 355.3 & 211.5 & 279.2 & 2180.3 & - \\
\hline C-15L-25FA-0 & 0.60 & 507.6 & 507.6 & 211.5 & 126.9 & 2230.0 & - \\
\hline C-33L-0FA-0 & 0.60 & 507.6 & 566.8 & - & 279.2 & 2244.1 & - \\
\hline C-15L-0FA-0 & 0.60 & 507.6 & 719.1 & - & 126.9 & 2293.8 & - \\
\hline C-33L-25FA-50 & 0.60 & 507.6 & 355.3 & 211.5 & 279.2 & 15.3 & 28.4 \\
\hline C-15L-25FA -50 & 0.60 & 507.6 & 507.6 & 211.5 & 126.9 & 65.0 & 28.4 \\
\hline C-33L-0FA -50 & 0.60 & 507.6 & 566.8 & - & 279.2 & 79.1 & 28.4 \\
\hline C-15L-0FA -50 & 0.60 & 507.6 & 719.1 & - & 126.9 & 128.8 & 28.4 \\
\hline C-33L-25FA -30 & 0.60 & 507.6 & 355.3 & 211.5 & 279.2 & 881.3 & 17.0 \\
\hline C-15L-25FA -30 & 0.60 & 507.6 & 507.6 & 211.5 & 126.9 & 931.0 & 17.0 \\
\hline C-33L-0FA -30 & 0.60 & 507.6 & 566.8 & - & 279.2 & 945.1 & 17.0 \\
\hline C-15L-0FA -30 & 0.60 & 507.6 & 719.1 & - & 126.9 & 994.8 & 17.0 \\
\hline
\end{tabular}

* C-aL-bFA-c: C = cement; aL = \% of lime in cementitious materials; bFA = \% of fly ash in cementitious materials; $\mathrm{c}=$ air content in total volume

** Cement factor (CF) was held to 9 


\section{Test Procedures}

Cellular Concrete (CC) cylindrical specimens of 101.6mm x 203.2mm (diameter x length) were prepared for compressive strength testing. Immediately after casting, the test specimens were covered to prevent moisture evaporation and placed in a moist-curing room at $23 \pm 2{ }^{\circ} \mathrm{C}$. Demolding was carried out 3 days after sample preparation. After demolding, the specimens were stored again at $23 \pm 2{ }^{\circ} \mathrm{C}$ and $100 \%$ relative humidity room until tested. The compressive strength was tested at ages 7,14 , and 56 days.

The Vacuum Saturation Method (similar with ASTM C 642) developed by Day and Marsh4 was used for determining the absorption and the porosity (volume of permeable pore space) of CC mixtures. After 14 days curing at $23 \pm 2{ }^{\circ} \mathrm{C}$ and $100 \%$ relative humidity room, specimens were dried in an oven at $100 \pm 5^{\circ} \mathrm{C}$ until constant weight had been achieved. After removing each specimen from the oven, the mass of oven-dried sample was measured. The specimens were immediately transferred to the desiccator filled with de-aired, distilled water, and vacuumed for at least 12 hours. The apparent mass of the sample in water after immersion and vacuuming was determined. Finally, the mass in air of saturated sample was determined by removing surface moisture with a towel. The absorption and porosity was calculated using Eq. (1) and Eq. (2), respectively:

$$
\begin{aligned}
& A=\frac{\left(W_{\text {sd }}-W_{\text {od }}\right)}{W_{\text {od }}} \times 100 \\
& P=\frac{\left(W_{\text {sd }}-W_{\text {od }}\right)}{\left(W_{\text {sd }}-W_{\text {water }}\right)} \times 100
\end{aligned}
$$

where, $A=$ absorption after immersion and vacuuming (\%); $P=$ vacuum saturation porosity (\%); $W_{\text {sd }}=$ weight of surface-dry sample in air after immersion and vacuuming; $W_{\text {od }}=$ weight of oven-dried sample in air; and $W_{\text {water }}=$ apparent weight of sample in water after immersion and vacuuming.

Freezing and thawing was performed according to ASTM C 1262-04 "Standard Test Method for Evaluating the Freeze-Thaw Durability of Manufactured Concrete Masonry Units and Related Concrete Units,” as well as to a slightly modified procedure. The modifications essentially concern the measurement of the relative dynamic modulus of elasticity of the specimens during the cycles. Four specimens per each mixture (total 40 specimens) were tested. Each specimen was completely submerged in water at $23 \pm 2{ }^{\circ} \mathrm{C}$ for 48 hours. Upon removal from the water, the specimen was weighed after the surface water on the specimen was removed with a damp cloth (the saturated weight). The specimens were then placed face down in the containers on the specimen supports and the water in the container was adjusted to $10 \mathrm{~mm}$ from the bottom of the CC specimen. The containers were sealed to prevent evaporation.

The specimens were frozen in a temperature-controlled freezer for 4.5 hours and thawed in an air for 7.5 hours. Two freezing and thawing cycles were conducted per day. Totally 60 cycles were applied to the specimens.

The relative dynamic modulus of elasticity of the specimens was measured at the end of every 6 cycles. The relative dynamic modulus of elasticity after c cylces, Pc, as a percentage of the initial value (at 0 cycles), can be computed as

$$
P_{c}=\frac{n_{c}^{2}}{n_{0}^{2}} \times 100
$$

where, $n_{c}=$ the fundamental transverse frequency after c cycles of freezing and thawing and $n_{0}=$ the fundamental transverse frequency at 0 cycles of freezing and thawing. 


\section{Test Results and Discussion}

Relationship between Dry Density and Water Absorption. Generally speaking, density, water absorption, and porosity are closely related to each other. With a decrease in density and an increase in porosity, the water absorption increases. The water absorption of CC mixtures is plotted as a function of dry density in Fig. 1. There is a good relationship between water absorption and dry density. It is obvious that the mixture with lower densities absorb significantly higher percentage of water than those with higher densities. It is also apparent that the mixture with higher $\mathrm{w} / \mathrm{cm}$ and fly ash has a trend of increased absorption and decreased density. This property needs further investigation because it may be connected to its durability in service. For instance, when the CC samples are exposed to wet and freeze-thaw attack environmental conditions, the absorbed water inside the CC sample can be frost damaged. Furthermore, the CC may show poor resistance to frost attack.

Porosity-water Absorption Relationship. In general, absorption capacity of concrete depends on a combination of pore sizes, uniformity of pore distribution, the continuity of the pore system, and other factors. When concrete is exposed to $\mathrm{F} / \mathrm{T}$ cycles, its water absorption is important for freeze-thawing damage to take place. Because the high porous concrete has a tendency to absorb much more water, it is vulnerable to frost damage because and free water in the larger pores freezes. The porosity of cellular concrete is the sum of macro and micro pores (capillary pore and gel pore) within the concrete. The water in the larger capillary pores and entrapped air voids of CC is critical and more susceptible to frost attack. Fig. 2 shows the relationship between porosity and water absorption of CC. An increase in the porosity leads to an increase in water absorption. However, higher porosity does not necessarily result in higher water absorption as linear regression analysis indicates a correlation coefficient of 0.36 for CC between porosity and water absorption. It should be noted that absorption is based on the volume of the open accessible pores exposed to water (the water content of the saturated paste expressed as a percentage of its weight), not on all the factors relative to absorption as previously mentioned.

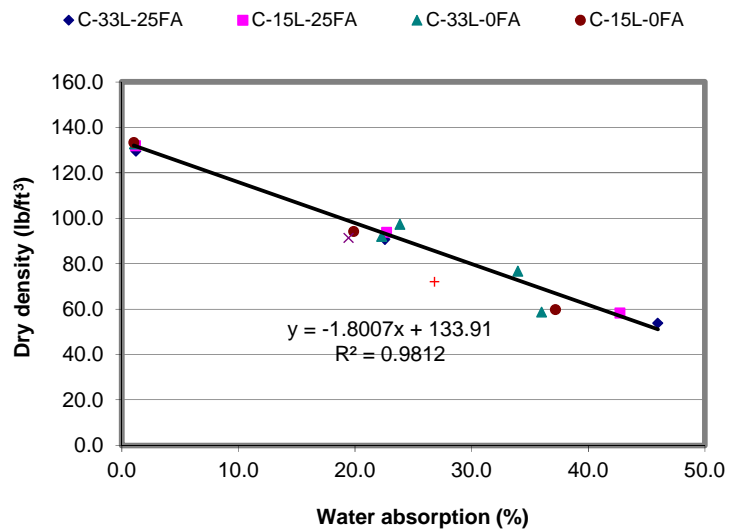

Fig. 1 Relationship between water absorption and dry density.



Fig. 2 Relationship between water absorption and porosity.

Compressive Strength Development. The compressive strength of cellular concrete mainly depends on its porosity and density, but other characteristics of the cementitious constituents may play a role as well. Fig. 3 and 4 provide compressive strength development of different CC mixtures. Cement and lime starts to contribute to strength development as early as 7 days after mixing, whereas fly ash takes more than 56 days to make any significant contribution to strength development. As expected, mixtures containing fly ash leads to low strength at early age and slow strength development for all curing period due to the slow hydration of fly ash. However, adding fly ash to the mixture improves late strength due to the pozzolanic reaction of fly ash. 


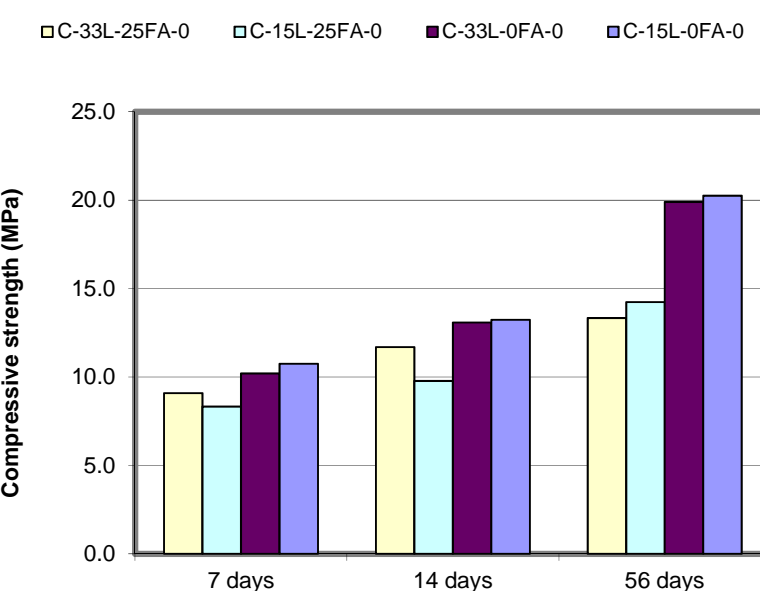

Fig. 3 Compressive strength development of Series I mixtures.

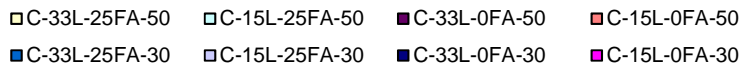

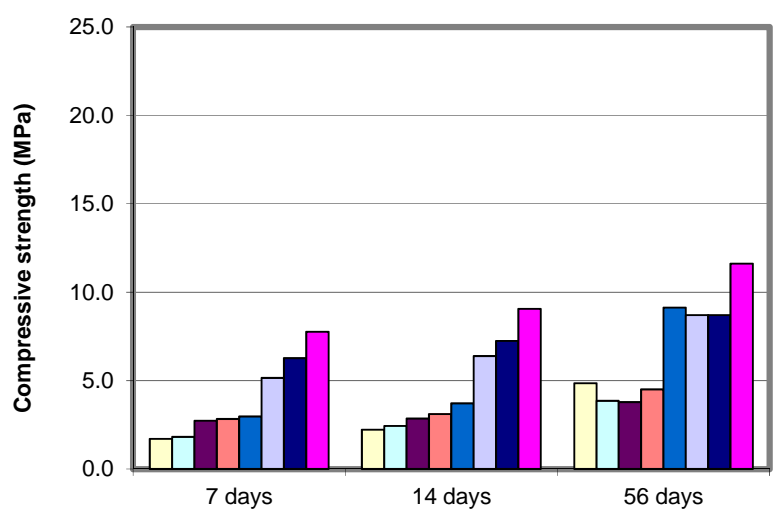

Fig. 4 Compressive strength development of Series II mixtures.

Freeze-thaw Resistance. Relative dynamic modulus of elasticity (RDME) value is expressed as the percent difference in the squares of the resonant frequency at any cycle compared with the initial frequency before freeze-thaw (F-T) cycling (Graybeal and Tanesi 2007). In general, the RDME of concrete increases slightly from 95 to $100 \%$ due to cement hydration, which densifies the concrete microstructure during the curing period. However, the RDME of concrete deteriorated due to developing internal microcracks caused by F-T attack as concrete specimen is exposed to F-T cycles. The test results of RDME for non-aerated mixture (Series I mixture) are given in Fig. 5. The RDME of non-aerated concrete specimens drops below 70 percent after 60 cycles. These results indicate that mild microcracking has occurred in the specimen. It should be noted that Series I mixtures has w/cm of 0.60 and the existence of a significant amount of freezable water in the cement paste's capillary pores might be responsible for progressive and disruptive internal pressure, which causes microcracking in concrete. On the other hand, the RDME for Series II mixture was above 70 percent at 60 cycles with showing very little mass loss as shown in Fig. 6. The good resistance of CC specimen to F-T action might be attributed to an improved air-void system in CC mixture. Like the entrained air bubbles, the micro and macro pores generated from foaming admixture might serve as reservoirs to receive disruptive internal pressure as it flows from the freezing sites.

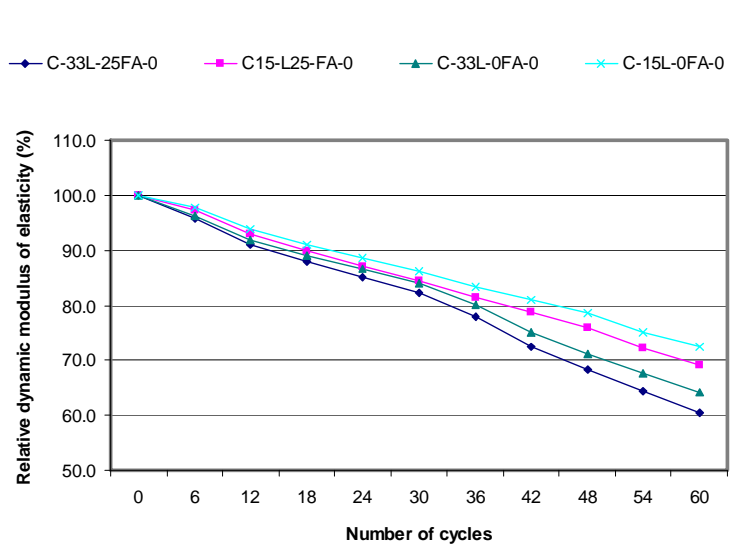

Fig. 5 Relative dynamic modulus of elasticity versus number of frost cycles for the non-aerated concrete (Series I mixtures).

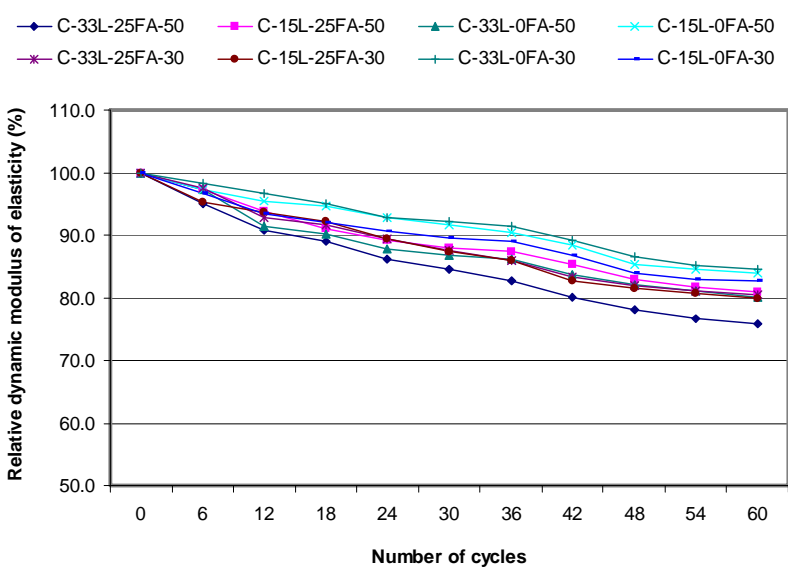

Fig. 6 Relative dynamic modulus of elasticity versus number of frost cycles for the non-aerated concrete (Series II mixtures). 


\section{Conclusion}

Based on the results of evaluation of frost resistance in cellular concrete containing cement-fly ash-lime, the following conclusions can be drawn: Compressive strength of cellular concrete is primarily as a function of the porosity and w/cm regardless of type of cementitious material and curing age. On the other hand, the CC mixture with high porosity does not necessarily result in higher resistance of F-T, but the CC concrete generally has good F-T resistance compare to non-aerated concrete.

\section{References}

[1] P. J. Tikalsky, J. Pospisil, W. MacDonald. A method for assessment of the freeze-thaw resistance of performed foam cellular concrete. Cement Concr. Res. 34(5) ( 2004) 889-893.

[2] N. Narayanan K. Rammamurthy. Structure and properties of aerated concrete: a review Cement Concr. Comp. 22(5) (2000) 321-329.

[3] M. Visagie E. P. Kearsley. Properties of Foamed Concrete as Influenced by Air-Void Parameters. Concrete/Beton 101 (2002) 8-14.

[4] E. K. Kunhanandan Nambiar K. Ramamurthy. Influence of filler type on the properties of foam concrete. Cement Concrete Comp. 28(5) (2006) 475-480.

[5] T. H. Wee, S. B. Daneti, T. Tamilselvan, H. S. Lim. Air void system of foamed concrete and its effect on mechanical properties. ACI Mater. J 103(1) (2006) 45-52.

[6] P. O. Guglielmi, W. R. L. Silva, W. L. Repette, D. Hotza. Porosity and Mechanical Strength of an Autoclaved Clayey Cellular Concrete. Adv. Civil Eng. 2010 (2010) 1-6.

[7] O. Senbu E. Kamada. Mechanism and evaluation method of frost deterioration of cellular concrete, durability of building materials and components. P. 5th Int. Conference. 1990, 241-246. 